\title{
Stigma in the Dutch Health Care Sector: HIV-Positive Substance Users' Experiences and Health Care Providers' Perspectives
}

\author{
Sarah E Stutterheim ${ }^{*}$, 2 , Hilde Roberts ${ }^{3}$, Ineke Baas ${ }^{3}$, Ronald Brands ${ }^{4}$, Jeannot Schmidt ${ }^{3}$, Lilian \\ Lechner ${ }^{1}$, Gerjo Kok ${ }^{2}$, Arjan ER Bos ${ }^{1}$ \\ ${ }^{I}$ Faculty of Psychology and Educational Sciences, Open University of the Netherlands, Heerlen, The \\ Netherlands \\ ${ }^{2}$ Department of Work and Social Psychology, Maastricht University, Maastricht, The Netherlands \\ ${ }^{3}$ Mainline, Amsterdam, The Netherlands \\ ${ }^{4} H V N$, Amsterdam, The Netherlands
}

\begin{abstract}
*Corresponding Author: Sarah E Stutterheim, Department of Work and Social Psychology, Faculty of Psychology and Neuroscience, Maastricht University, Maastricht, The Netherlands. Email: s.stutterheim @ maastrichtuniversity.nl
\end{abstract}

\begin{abstract}
We explored 15 HIV-positive substance users' experiences with health care alongside the perspectives of 14 health professionals. Substance users with HIV reported positive and negative experiences. Positive experiences included equal treatment, receiving social support and extra care, and good continuity of care. Negative experiences included being met with fear and apprehension, excessive or differential precautions, unnecessary referrals, outright care refusal, confidentiality breaches, and poor care provision. Health professionals reported limited experience caring for substance users with HIV. Most spoke generally about substance users, claiming that they can be difficult clients who are demanding, impatient, unpredictable, and untrustworthy. Also, health professionals indicated that substance users can be shoppers in search of unnecessary prescriptions or avoiders of health care. Efforts to improve interactions should encourage positive contact, and should focus on combating attributions of personal responsibility, creating an awareness of behaviors that are stigmatizing, and improving knowledge of occupational risks for HIV.
\end{abstract}

Keywords: HIV, AIDS, stigma, stigmatization, substance use, drug use, health care,

\section{INTRODUCTION}

Stigmatization is a socially and culturally constituted process by which a person is labelled as different and then devalued, leading to status loss and discrimination [1, 2]. There are a number of conditions that elicit negative or stigmatizing reactions from others. One such condition is substance use. In fact, substance use is, compared to other conditions, one of the most stigmatized [3,4]. It is 'strongly moralized' [5] and often seen as a condition over which one has personal control [6]. Consequently, substance users are frequently viewed as weak and immoral people that can be held personally responsible for both the onset and continuation of their substance use dependence $[3,7,8]$. This, in turn, can result in less sympathetic and more stigmatizing reactions from others [9].

Another condition that is highly stigmatized is HIV. The literature on the stigmatization of people living with HIV (PLWH) is extensive and has demonstrated that HIV is perceived to be highly contagious and very severe. These perceptions often combine with moral judgments about how HIV is acquired and the behaviours with which it is frequently associated (i.e., injecting drug use, homosexuality, sex work) to generate emotional responses of fear and anger that, in turn, lead to stigmatizing behavioural reactions such as avoidance, exclusion, and blame [9-13].

Often, becoming infected with HIV is considered a natural consequence of irresponsible and immoral behaviour and, thus, HIV can be seen as a marker for current or previous norm-violating behaviours like substance use [14]. In this context, HIV-related stigma is inseparable from substance use stigma, and indeed, the two can be found in combination with one another, yielding what is called layered stigma $[15,16]$. When the stigmas of HIV and substance use are layered, they become interdependent and interact with one another to yield significant negative outcomes [17]. 
Previous research has shown that people living with HIV who use substances (e.g., cocaine, heroin, methadone, morphine) experience stigmatization across a broad range of settings, including with friends, with family, with other substance users, in social services, in detention facilities, and in health care settings [3, 18]. Stigmatization in health care settings, in particular, has been found to be highly detrimental to the well-being of substance users with HIV [8, 19]. In fact, anticipated or enacted stigmatizing reactions from health care professionals can inhibit both substance use dependence treatment and HIV care [8, 20, 21] through testing delays [22, 23], treatment avoidance [19, 24, 25], late entry into care [24], non-disclosure of substance use and/or HIV status $[19,21,26]$, and poor access to antiretroviral therapy [27], all of which also impede HIV prevention efforts [19, 28]. It is therefore important to engage in efforts to reduce the stigmatization of substance users with HIV in health care settings, and to improve interactions between health care professionals and substance users with HIV. In order to do this effectively, an understanding of how these interactions are perceived is necessary [29]. The current literature on HIV-positive substance users' experiences in health care settings is relatively limited, as is the literature on health care providers' perceptions of substance users with HIV. The purpose of the study reported here was to explore HIV-positive substance users' experiences with health care providers in the Netherlands and to compare these experiences with the perspectives of health care providers regarding their interactions with substance users. Combining the perspectives of both substance users with HIV and health care providers is something that, to our knowledge, has not frequently been done but is nonetheless imperative to gaining a fuller understanding of how substance users with HIV and health care providers interact [30].

\section{Method}

\section{Study Design and Context}

The perspectives of both substance users with HIV and health care providers were explored qualitatively using a general inductive approach [31] with no formal ontological orientation [32]. Our purpose was to better understand the experiences of substance users with HIV and the perspectives of health care providers such that the insights from this study could be serve as input for improved health care interactions and thus our methods were practice-driven rather than guided by a given ontological orientation (e.g, grounded theory, discourse analysis) [32]. Ethical approval was provided by the ethics board at the Open University of the Netherlands' former Faculty of Psychology. Substance users with HIV received a small monetary compensation of $€ 10$ and health care professionals received a small gift of similar value.

The context within which our study was conducted was the Dutch health care sector. HIV prevalence is relatively low in the Netherlands with 18,355 people known to be enrolled in specialized HIV care as of May, 2015. In the Netherlands, AIDS is uncommon. Of the 18,335 patients with HIV, most reported having acquired HIV through sex (MSM = 11,204 [61\%]; heterosexual = 5,414 [29\%]). A small portion $(n=399 ; 2 \%)$ of PLWH in care in the Netherlands reported having acquired HIV through intravenous drug use [33]. As a result of low prevalence rates and the provision of specialized HIV care, most health care providers in the Netherlands have limited if any contact with substance users with HIV unless they are specialized in HIV care [34] or substance use dependence, which is generally a distinct area of psychological care services.

\section{Recruitment and Data Collection}

Between March and October of 2011, JS, a male staff member with extensive experience in the provision of social services to substance users at Mainline, which is an organization that seeks to improve substance users' health and quality of life, recruited, in person, during contact with clients at Mainline, a convenience sample of 15 HIV-positive substance users, none of which had AIDS, for one-on-one semi-structured interviews. Most of the interviews $(n=12)$ occurred face-to-face at a location chosen by the participant. The remaining three interviews were conducted by telephone. Interviews were preceded by informed consent and a short survey that measured demographic characteristics (i.e., age, gender, educational attainment, employment, ethnicity, sexual orientation, location, and family composition), HIV-related characteristics (i.e., means of transmission, time since diagnosis, treatment status, current health status, and presence of visible symptoms), and current substance use. Interviews were guided by a structured protocol with follow-up probes. Topics included 1) positive responses to HIV by health 
professionals, 2) negative responses to HIV by health professionals.

To complement the data acquired from substance users on their interactions with health professionals, SS, a female postdoctoral researcher with significant experience in conducting qualitative health research, recruited and interviewed 14 health professionals between January and March of 2012. Health care professionals were recruited using a snowball sampling technique via social media (i.e., Facebook, LinkedIn). The interviews were oneon-one and semi-structured. Each interview was approximately 30 minutes and took place at a location selected by the participant, which was usually his or her place of employment or home. These interviews were preceded by informed consent and guided by a structured protocol with follow-up probes. Topics discussed in the interviews with health care professionals were 1) previous experience with substance users, PLWH, or substance users with HIV; and 2) expectations in future interactions with substance users, PLWH, or substance users with HIV.

Most of the interviews were recorded using a digital voice recorder and then transcribed verbatim. However, three substance users with HIV objected to being recorded. Rather than excluding those participants from participation in an interview, we opted to take detailed notes instead and included those notes in our analyses. Additionally, due to technical difficulties, the recordings from two interviews with substance users stopped prematurely without the knowledge of the interviewer. Consequently, no notes for the unrecorded remainder of those interviews were taken. $\mathrm{We}$ decided to nonetheless include the recorded data from those interviews (length: 17 minutes and 34 seconds and 24 minutes and 15 seconds) in our analyses as certain topics had been fully discussed in the recording and discarding that information would entail discarding rich and relevant data. In an interesting conference proceeding, Crow and Powell [35] argued that gaps in transcription happen and that not only the remaining data but also the unrecorded data can be considered in analyses. We erred on the side of caution and only included the information recorded in those partially recorded interviews.

\section{Data Analyses}

SS processed the data using QSR Nvivo 8®, adopting a general inductive approach to conduct thematic analyses [31]. This meant that each transcript was read while listening to the corresponding recording to identify themes and determine categories to which text could be assigned. As coding occurred, categories and subcategories were developed and linked to one another, resulting in a coding tree (see Figure 1). To promote rigour, a decision trail was maintained via annotations and memos. All emergent categories were documented, as were changes made to categories and reasons for changes, and both the established categories and their development were discussed by SS and AB. Later, preliminary findings were discussed with the research team and then compared to findings reported in the empirical literature and with professionals working with substance users (i.e., a member check).

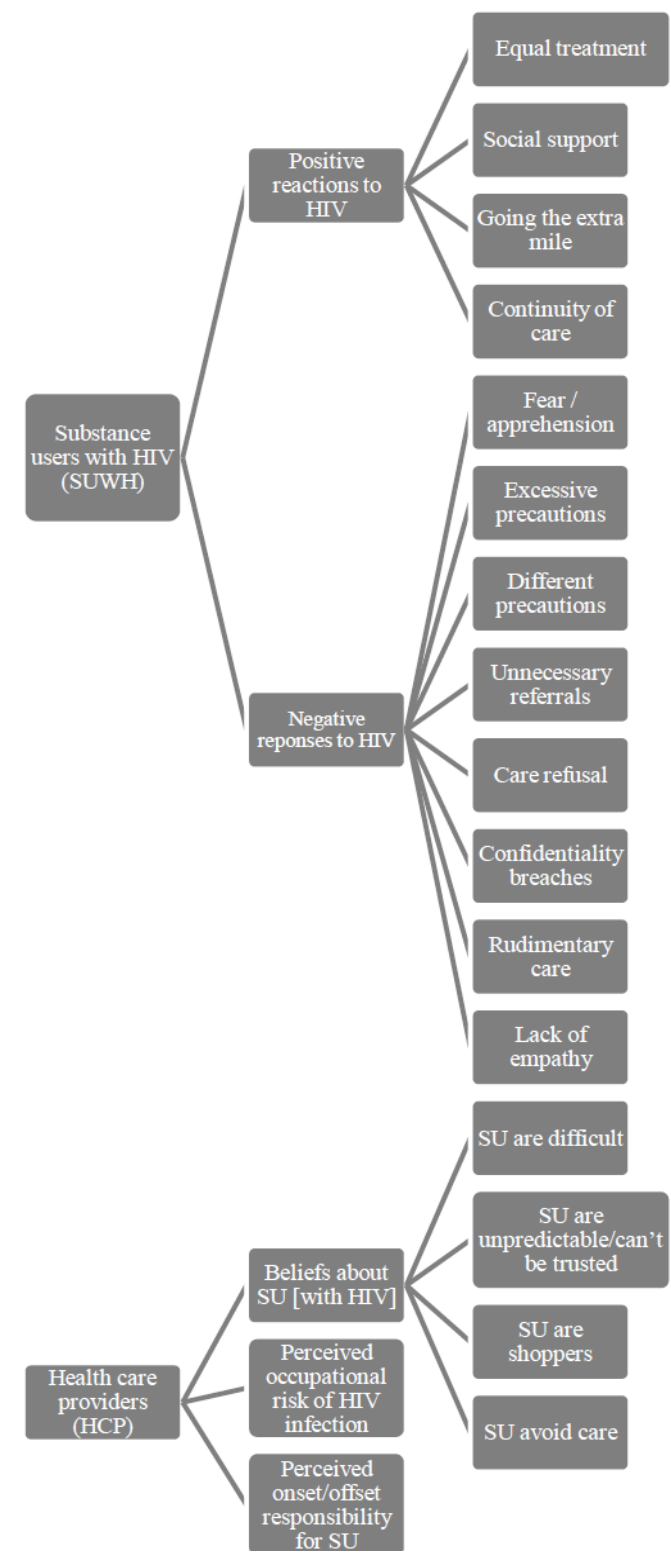

Figure1. Coding Tree 


\section{RESUlTS}

\section{Participant Characteristics}

In the subsample of 15 substance users with HIV, 10 were men and 5 were women. Most were Dutch $(n=13)$. All participants lived an urban centre, usually Amsterdam or Rotterdam. With regard to sexual orientation, 11 selfidentified as straight, 2 as bisexual, 1 as gay, and data were missing for 1 other participant. Participants ranged in age from 41 to 62 with a mean age of 50.6 years $(S D=7.1$; data missing for 3 participants). Also, 11 participants were single (data missing for 1 participant) and only 2 had children (data missing for 1 participant). In terms of educational attainment, 7 had less than a high school education, 5 had a high school diploma and/or some vocational training, and data on education were missing for 3 remaining participants. Regarding means of transmission, 8 had acquired HIV through sexual intercourse, 3 through intravenous drug use, 3 were unsure of how they had acquired HIV, and data were missing for 1 other participant. The mean time since diagnosis was 19.0 years prior to the interview $(S D=4.3)$ and most participants were polydrug users. Substances reported to be used included cocaine, heroin, methadone, morphine, marijuana, and benzodiazepines including diazepam (Valium).

The 14 health care professionals recruited and interviewed included physicians (i.e., general practitioners, an anaesthesiologist, a paediatrician, and a psychiatrist), (specialized) nurses, nursing assistants, a nurse manager, and a dentist. All of the health professionals were Dutch; 10 were women and 4 were men. Ages ranged from 24 to 66 with a mean age of 38.6 years $(S D=11.7)$. Given their occupation, all had a bachelor's degree or more. Half were working full-time when interviewed; the other half worked part-time.

\section{Interactions in Health Care: Substance Users with HIV's Perspectives}

Substance users with HIV conveyed a number of positive and negative experiences surrounding their HIV infection in their interactions with health care professionals. These are summarized in Table 1.

Positive Experiences: Most substance users with HIV reported positive experiences with health care providers. Generally, they reported feeling they had been treated like any other patient. One participant said:
I've never had that feeling, like, shit, I shouldn't have told them that I'm sick, that I have HIV and hepatitis $\mathrm{C}$ or whatever. People have always taken me as I am and I've never felt that people treated me differently because I told them. (Theo ${ }^{1}$, age 43).

Similarly, Bart said, 'I haven't experienced that. No, most of the doctors and specialists that have come to my bedside, you know, they've always dealt with it well' (Bart, age 49). Specific positive experiences, beyond being treated like any other patient, that were reported included receiving social support and extra care whenever necessary: 'There are people who indeed go the extra mile. ... That if I am there [GP's office], he always takes his time with me, even if it's the walk-in hour for prescriptions and referrals' (Tim, age 51).

Additionally, among participants that had previously spent time in detention facilities, good continuity of care was reported: 'The medical services there are totally in the know and with check-ups at the hospital and all - it's just really well organized' (Theo, age 43).

Fear and Apprehension: Unfortunately, the substance users with HIV in our study also reported negative experiences. Some participants discussed sensing, or having experienced, fear and apprehension in care for people with HIV among doctors, nurses, dentists, phlebotomists, and others. For example, Nikki reported the following incident with a dentist:

He went to fill some cavities and was using one of those hooks and he said, 'Did you see that? Did you see that?' I said, 'No. What?' 'I almost pricked my finger. That would not make me happy. Then I wouldn't be so nice to you.' I said, 'Well, I have to say, Mr. [name removed], that is your error. You need to just be careful and not freak out. (Nikki, age 44)

Similarly, Simon conveyed the following:

If you have a cut, they'll give you a tissue so that you can wrap it around

\footnotetext{
${ }^{1}$ Names have been changed to protect the identity of participants.
} 
instead of them doing it for you because they know that you have HIV and they know that the minute there's contact, it could be dangerous for them. An alarm goes off: Danger! Danger! Danger! And although they're pretty good at hiding it, they can't totally get rid of it. (Simon, age 60)

Excessive and Differential Precautions: Some substance users with HIV also reported feeling they had been treated differently than other patients. For example, Laura reported an experience that led her to believe that gloves had been used with her but not with other patients:

Two years ago, I was in the hospital. [I was] so sick, and there was something with my arm. And a women from the OR [operating room] came to give me a drip. In the hall, she was told, 'You have to you have to wear gloves, eh? Because the lady has HIV.' (Laura, age 44)

Similarly, Tim reported being treated differently in a dental practice:

And then it's planned in at four o'clock in the afternoon. Of course they should always - They have to treat every patient as if he has HIV and hepatitis and whatever other scary diseases that you can think of, but, of course, in reality, uh, yeah, everything is disinfected and blah blah blah but there's a glass of water that you drink out of and do you know how it was washed? No, you don't. And, so what do they do to avoid any risks? Well, they put me at the end of the day 'cuz then they can sterilize and disinfect everything really well. (Tim, age 51)

Some substance users with HIV reported very extreme cases of excessive precautions such as the separation of dishes and cutlery, being placed in an isolation room, and the use of excessive personal protective equipment (i.e., gowns, caps, plastic shoe covers, etc.) but most of these experiences were reported to have occurred in the early years of the HIV epidemic. Fortunately, the more recent experiences were not as blatantly stigmatizing but did often reflect a fear of occupational exposure to HIV (e.g., using gloves with PLWH and not with other patients) and a lack of knowledge regarding how to adequately care for substance users with HIV.
Unnecessary Referrals and Refusal to Provide Care: In addition to the application of excessive and differential precautions, substance users with HIV reported having been unnecessarily referred to other health care providers:

Well, my dentist, I haven't seen him since [disclosing my HIV status]. He doesn't want anything to do with me. I'm always sent directly to the dental surgeon. That even happened just three weeks ago. I walked into a dentist's office and I said, 'Do you guys have room?' Yup, they did. I said, 'I mean I need dentures.' Well, that wasn't a problem. Blah blah blah. I just needed to wait for a little bit. 'You'll be helped soon.' Then, 'Would you please fill in these forms?' That was a whole thing about what kind of medicine you take. Blah blah blah. And, uh, I thought, you know, I can lie and I'm totally not obliged to fill it in but I didn't feel like lying. Let them figure it out. So, I filled it in and what medication I take, where, what kinds of conditions I'm being treated for. And yeah, well, it was, 'Yeah, it's kind of scary and you could bleed for longer and we think it's better if we refer you to a dental surgeon.' (Tim, age 51)

Occasionally, substance users with HIV were outright refused by health care providers without a referral to someone else. Francis explained, 'Once, I had that happen with a pedicure. They first wanted to find out if they could do my feet with their machines' (Francis, age 41). He was subsequently refused care. Again, extreme incidents with, for example, nursing staff in hospitals refusing to treat substance users with HIV were reported to have occurred but not in recent years indicating that there have indeed been improvements over time.

Breached Confidentiality: Substance users with HIV further reported breaches of confidentiality where by health care professionals had, without consent, informed others of their HIV status: 'At one point, my GP [general practitioner] told my mother' (Andre, age unknown). Sometimes confidentiality breaches occurred within health care facilities and appeared to be done in an effort to warn other health professionals about a possible occupational risk of infection. Laura mentioned, 
'On the outside of my file, there were big letters in capitals: HIV' (Laura, age 44).

Poor Care Provision: Substance users with HIV further conveyed incidents of poor care provision that, in their opinion, were representative of a lack of sympathy and empathy. Nikki, for example, said she had been bombarded and indirectly held responsible for the possible implications of a needle stick injury:

In a total panic, they came to me. 'Yeah, an intern had a needle stick injury and we need to know right now what medication you take, what combination.' And you feel so horrible when you hear that, eh? And then, to add to it, they say, 'Yeah, he just had a baby.' ... They could have looked it up in my file. It's simple enough because I was being treated for everything right there so they totally didn't need to come to my bed but, because of the panic, they thought they needed to figure it out right away. 'We're best off asking her directly.' And then, on top of that, telling me about that little baby as if they mean to say, 'You should think long and hard about your HIV and AIDS.' (Nikki, age 44)

Two other participants reported receiving almost rudimentary treatment whereby local anaesthesia was not administered and, in their opinion, should have been. Another participant spoke of being inadequately counselled after receiving his diagnosis:

They also said, 'You know what the worst part is? I have rotten news for you and I don't even have time to sit and talk with you about it 'cuz you've seen how busy it is out there in the hall.' She said, 'I just don't have time right now.' (Simon, age 60)

Lastly, one participant conveyed feeling dismissed by her occupational therapist:

The doctor, the company doctor said I couldn't work anymore because I was HIV-positive and I had this and that and, yeah, because people wouldn't want to hire me and they'd think - yeah - or they don't know how long you'll live or if you'll miss lots of work because you're sick. (Laura, age 44)
Table 1. HIV-positive substance users' perspectives

\begin{tabular}{|l|l|}
\hline Positive experiences: & Negative experiences: \\
\hline $\begin{array}{l}\text { Being treated like any } \\
\text { other patient }\end{array}$ & $\begin{array}{l}\text { Met with fear and } \\
\text { apprehension }\end{array}$ \\
\hline $\begin{array}{l}\text { Receiving social } \\
\text { support }\end{array}$ & Differential precautions \\
\hline $\begin{array}{l}\text { Receiving extra care } \\
\text { when necessary }\end{array}$ & Excessive precautions \\
\hline Good continuity of care & Unnecessary referrals \\
\hline & Refusal to provide care \\
\hline & Breached confidentiality \\
\hline & Lack of empathy \\
\hline \multicolumn{2}{|c|}{ Realth Care: Health } \\
Interactions in \\
Professionals' Perspectives
\end{tabular}

Most health care professionals had some but not extensive experience in caring for substance users and very limited or no experience caring for substance users with HIV. Consequently, most spoke generally about their perceptions or expectations of substance users. A few themes presented in this regard. These are summarized in Table 2.

Difficult Clients: First, substance users, both those with HIV and those without, were frequently considered difficult clients: 'That's a group that can bring about irritation at the front desk and among the assistants' (Niels, general practitioner, age 52). In that context, substance users were considered demanding and impatient:

It's often those very patients that don't take good care of themselves at home that demand a lot from us. They seem to think that they've landed themselves in a hotel [referring to the hospital in which she works] and that we'll do anything for them. They want to have everything. They're quite demanding about what they want to eat and drink. (Lori, nurse, age 24)

\section{Unpredictable and Untrustworthy:}

Additionally, substance users (with HIV) were perceived by some to be unpredictable and untrustworthy. One nurse said:

We have to be on our guard because sometimes those people do really weird things. We've had someone that injected alcohol into his drip and stuff so, yeah, those are things we have to be careful about and watch for. (Lori, nurse, age 24)

This same nurse also reported having to be wary of illegal substance use in care facilities: 
We've had people who are addicted and then someone comes to visit and brings drugs with them. We have to really watch for that because they then go and use drugs while on our ward and we're basically responsible for them while they're in our care. (Lori, nurse, age 24)

Similarly, another nurse spoke of being particularly watchful of the medicine cart when substance users are in her care:

And then I heard that that man was addicted to heroin and was getting methadone and, yeah, after that, I was more careful than I normally am, especially with the medicine cart, and I was especially careful with what we gave him, that it was registered properly. (Ria, nurse, age 24)

Substance Users as Health Care Shoppers and Avoiders: In similar vein, health care providers reported perceiving some substance users (with HIV) to be shoppers:

Drug users naturally are, you know, generally speaking, difficult clients in the sense that they sometimes ask for medication - they come here with shopping behaviour. So, they come here while they really should be elsewhere for the problem they come for and then they try to, through the GP, score sleeping pills and stuff. (Niels, general practitioner, age 52)

Substance users were further considered to be difficult because they are perceived to avoid necessary health care services. In the words of one health professional:

It's often very difficult because they're care avoiders. ... It's not important to them. If they're still addicted, then what's most important is scoring every day so that's their priority. They only consider their health to be important once they're detoxed. (Anne, nurse, age 38)

Fear of Occupational Infection: The health professionals in our study also reported wanting to be extra careful with substance users because they are more likely to have HIV: 'We would never let an intern do a drip, primarily because of the risks. You never know what someone could have, especially with those people' (Ria, nurse, age 24).

Personal Responsibility: In addition to perceiving substance users as difficult, demanding, unpredictable, untrustworthy, negligent of their health, and sources of undesirable infections, health care professionals also conveyed how substance users are often blamed for their substance use dependence by not only the general public but also by health care providers:

There's a lot of blame. I have a woman in our facility and she's pregnant and using speed and cocaine and, even now, while she's very, very pregnant. She's due any day and still does that. She just smuggles it in. Yeah, then you notice a lot of the nursing staff are very judgmental about it. They can't comprehend it: 'How can she do that?!?' They don't consider what addiction entails, that people don't choose to use. They can't help but to use. (Hugo, age 32, physician)

Fortunately, and as exemplified by Hugo's statement, a number of professionals interviewed did recognize the powerlessness of substance use dependence. Simply put, Peter said 'Lots of people think that it's their own fault but that's not the case' (Peter, nurse, age 66).

Health care professionals also conveyed the importance of remaining non-judgmental in their care for substance users:

I always try to be as neutral as possible because, I mean, people, you know - I can't judge why someone's used heroin and I can't pass judgment and know why that person can't resist the addiction. I can only imagine that it's really difficult. (Ellin, physician, age 33)

Table 2. Health care providers' perspectives

\begin{tabular}{|l|}
\hline Substance users can be difficult clients \\
\hline Substance users can be unpredictable \\
\hline Substance users can be untrustworthy \\
\hline Substance users can be shoppers \\
\hline Substance users can be care avoiders \\
\hline Substance users can carry infectious diseases \\
\hline Substance users may be blameworthy \\
\hline $\begin{array}{l}\text { Substance users may be powerless over their } \\
\text { substance use dependence }\end{array}$ \\
\hline It is important to remain non-judgmental \\
\hline
\end{tabular}

\section{DISCUSSION}

Our findings have demonstrated that substance users with HIV have had both positive and negative experiences with health care providers. Positive experiences included being treated like any other patient, receiving social support and extra care, and encountering good continuity of 
care. Negative experiences included being met with fear and apprehension, the use of excessive or differential precautions, unnecessary referrals to other health care providers, outright care refusal, confidentiality breaches, and poor care provision representative of a lack of empathy. These findings are similar to those of Stutterheim et al. [34] who reported on positive and negative interactions between nonsubstance using people with HIV and health care professionals. In that study, positive experiences reported included receiving equal treatment, being valued as a partner in one's health, social support provision, and confidentiality assurances while negative experiences included awkward interactions, irrelevant questions, rude treatment, blame, pity, excessive or differential precautions, care refusal, unnecessary referrals, delayed treatment, poor support, and confidentiality breaches. Our current findings are also similar to findings from studies that have investigated health care provision to substance users more generally [6, 36-38] as well as studies looking at the interactions between health care providers and substance users with HIV specifically [18$20,27]$. For example, previous research has shown that substance users have been refused services or prescriptions [6], that substance users have been provided with less information than others and have received poorer quality care [37], and that HIV diagnoses have been provided to substance users in a detached and unsympathetic manner [18].

The health care professionals included in our study reported having some experience caring for substance users and often no experience caring for substance users with HIV. Consequently, most spoke generally about their perceptions of substance users. In this context, health care providers reported that substance users can be difficult clients who are demanding, impatient, unpredictable, and untrustworthy. Also, health care providers reported that, in health care, substance users are often viewed as shoppers in search of prescription medications for recreational use or avoiders of necessary health care. Such perceptions have been documented earlier. For example, in their review of substance use stigma, Livingston et al. [6] reported that health professionals often think that substance users will fail to adhere to the care recommended, that they are not vested in their own health, that they abuse the system through drug-seeking behaviours, and that they overuse system resources. Similarly, Wolfe and colleagues [39], in their discussion of barriers to care for injecting drug users with HIV, stated that some health care providers see substance users as troublesome and noncompliant. Unfortunately, these perceptions reflect incorrect stereotypes. Two meta-analyses, one exploring adherence to antiretroviral therapy among drug users with HIV and one exploring the development of antiretroviral resistance (as a marker for nonadherence) among injecting drug users with HIV, have solidly established that adherence and antiretroviral resistance rates among drug users do not differ significantly from adherence and antiretroviral resistance rates among PLWH who do not use drugs [27, 40]. Unfortunately, pervasive stereotypes labelling substance users as noncompliant individuals with poor adherence to therapy remain and they are not only incorrect but also detrimental contributors to stigmatization because they reinforce a distinction between 'us' and 'them'.

The health care providers included in our study also reported that some health care providers feel the need to be extra careful with substance users because they are more likely to have HIV. Additionally, the health care providers in this study conveyed how substance users are often blamed for their substance use dependence not only by the general public but also by health care providers. This corresponds with a significant body of literature demonstrating a discourse of agency and 'deservingness' as it pertains to substance use itself, and the consequences of substance use including the acquisition of HIV. Often, substance users are perceived by not only broader society, but also by health care professionals, to have control over their substance use $[6,41,42]$ and to have brought their HIV infection upon themselves $[39,43]$. Consequently, they are often considered less worthy of support. A lack of compassion toward substance users with HIV as a result of attributions of personal responsibility for substance use and HIV infection is in line with the cognitive-emotional model of HIVrelated stigmatization posited by Bos, Schaalma, and Pryor [11]. This model claims that attributions of personal responsibility yield less compassion, more anger, and subsequently, greater stigmatization. Fortunately, in our study, a number of health professionals recognized the powerlessness of substance use dependence and 
the importance of remaining non-judgmental when caring for substance users. Viewing substance use dependence as a medical condition deserving of treatment is important not only because it shifts the blame or responsibility away from the substance user but also because the perception that a stigmatized condition is treatable has been found to be associated with reduced stigmatization [44].

Taking the findings into consideration, we contend that efforts should be made to improve interactions between substance users with HIV and health care providers. The improvement of these interactions requires the development and implementation of multi-layered interventions $[17,45-48]$ in health care settings that are underpinned by political will, financial support, and the commitment of institutions to stigma reduction [37, 49]. These kinds of macro supports for interpersonal and organizational interventions are imperative if interventions are to be successful. Interventions should also be characterized by target user participation [11, $36,38,48]$.

Specifically, we believe that, based on our findings and the literature, efforts to reduce the stigmatization of substance users with HIV in health care settings should focus on combating, among health care providers, attributions of personal responsibility and blame for both substance use dependence and the acquisition of HIV. As our findings have shown, such attributions are not only felt by substance users with HIV but also expressed by health care providers, and the literature supports this contention [6, 39, 41-43]. The literature also demonstrates how this discourse of agency can negatively impact the health and well-being of substance users with HIV and inhibit HIV prevention efforts [19, 22, 24, 25, 27, 28, 41]. Tackling such attributions of personal responsibility is thus paramount. It is therefore important that, through stigma reduction interventions, health care providers come to recognize substance use dependence as a bonafide health problem that is shaped by a number of biological, physiological, sociopolitical, and structural factors [42].

We further recommend offering sensitivity training to health care professionals and students of health care professions that promotes an awareness of behaviours that can be perceived as stigmatizing and that allows for reflection upon one's own attitudes toward substance use and HIV infection [41]. We believe that such training can be embedded in broader efforts to promote quality care marked by respect and dignity [50] and should focus on increasing cognizance of layered stigma and its impact [43]. This is important because focusing on HIV-related stigma alone is likely to be insufficient to improve interactions with HIVpositive substance users given that previous findings have shown that substance use stigma is greater than HIV-related stigma [3, 43, 51]. Also, we believe that sensitivity training should seek to reframe substance users' engagement with health care services as a pro-active and positive health-focused action rather than as difficult instances with demanding, impatient, unpredictable, and unreliable shoppers [38]. In that context, the training should explicitly convey that substance users are not prototypically unreliable but that they are able to adhere to (HIV) treatment regimens as well as non-substance using patients [27, 40].

In addition to sensitivity training, we recommend that stigma reduction interventions geared to health care providers tackle health care providers' fear of occupational infection by providing information on actual occupational risks, infection prevention measures, and postexposure prophylaxis [20, 34].

As for the form that stigma interventions geared to health care providers should take, we recommend, in line with previous recommendations made on reducing HIVrelated stigma in health care settings [34], that such interventions be short and easy to access. They should comprise not only information provision but also an aspect of direct (one-onone) or vicarious (digital) contact between health care providers and substance users with HIV [11, 34, 52]. The provision of not only information but also opportunities for contact is particularly important in light of Ding et al.'s [20] study demonstrating that both the expertise (i.e., knowledge) and experience (i.e., previous contact) of physicians predicts the quality of care provided to substance users with HIV. Similarly, in their investigation of health care students' attitudes towards patients at high risk for HIV, Jin et al. [51] found that health care students who knew someone with HIV or knew someone who injects drugs were more likely to report positive attitudes. This clearly supports the inclusion of contact in interventions geared to health care providers. 
Our findings should be interpreted in light of a few limitations. First, the technical difficulties experienced during data acquisition may have impacted our findings. A second limitation is the variation in the means by which data were acquired for the interviews with substance users with HIV. Some interviews were conducted in person and recorded, others were conducted in person without a recording, and still others were conducted by telephone. It is possible that the data derived from participants that refused to be recorded differed from the data derived from participants that agreed to be recorded or that the data acquired by telephone differed from the data acquired in person. However, we believe that, for substance users with HIV who refused to be recorded, knowing that there no verbatim record of their interview was present may have, in fact, encouraged them to speak more openly about their experiences. In similar vein, the increased anonymity associated with telephone interviews may have encouraged participants interviewed by telephone to speak more openly than those interviewed in person. However, our impression was that all substance users with HIV spoke candidly about their experiences and the interviewer (JS) did not report noting substantial differences between those who were recorded in person, those interviewed by telephone, and those who refused to be recorded.

In conclusion, this study has explored substance users with HIV's perspectives on their interactions with health care professionals as well as health care professionals' perspectives on, and expectations regarding, interactions with substance users with HIV. It has also shown that, despite many positive interactions, negative interactions, likely driven by stereotypes about substance use and HIV, do occur and should be targeted for intervention.

\section{ACKNOWLEDGEMENTS}

This study was made possible by Aidsfonds (grant number 2009083). The authors wish to acknowledge all study participants and LissaAgema at Transcriptieservice.nl who transcribed the interviews.

\section{REFERENCES}

[1] Pescosolido, B.A. and J.K. Martin, The Stigma Complex. Annual Review of Sociology, 2015. 41: p. 87-116.

[2] Link, B.G. and J. Phelan, Stigma power. Social Science \& Medicine, 2014. 103: p. 24-32.
[3] Stutterheim, S.E., et al., Stigma experiences among substance users with HIV. Stigma \& Health, 2016. 1(3): p. 123-145.

[4] Parcesepe, A.M. and L.J. Cabassa, Public Stigma of Mental Illness in the United States: A Systematic Literature Review. Administration and Policy in Mental Health and Mental Health Services Research, 2013. 40(5): p. 384-399.

[5] Kulesza, M., M.E. Larimer, and D. Rao, Substance Use Related Stigma: What we Know and the Way Forward. Journal of Addictive Behaviors, Therapy \& Rehabilitation, 2013. 2(2).

[6] Livingston, J.D., et al., The effectiveness of interventions for reducing stigma related to substance use disorders: a systematic review. Addiction, 2012. 107(1): p. 39-50.

[7] van Boekel, L.C., et al., Public opinion on imposing restrictions to people with an alcoholor drug addiction: A cross-sectional survey. Social Psychiatry and Psychiatric Epidemiology, 2013. 48(12): p. 2007-2016.

[8] Ahern, J., J. Stuber, and S. Galea, Stigma, discrimination and the health of illicit drug users. Drug and Alcohol Dependence, 2007. 88(2-3): p. 188-96.

[9] Dijker, A.J. and W. Koomen, Extending Weiner's attribution-emotion model of stigmatization of ill persons. Basic and Applied Social Psychology, 2003. 25(1): p. 51-68.

[10] Bos, A.E.R., A.J.M. Dijker, and W. Koomen, Sex differences in emotional and behavioral responses to $\mathrm{HIV}+$ individuals' expression of distress. Psychology \& Health, 2007. 22(4): p. 493-511.

[11] Bos, A.E.R., H.P. Schaalma, and J.B. Pryor, Reducing AIDS-related stigma in developing countries: The importance of theory- and evidence-based interventions. Psychology, Health \& Medicine, 2008. 13(4): p. 450-60.

[12] Stutterheim, S.E., et al., Beliefs contributing to HIV-related stigma in African and AfroCaribbean communities in the Netherlands. Journal of Community \& Applied Social Psychology, 2012. 22(6): p. 470-484.

[13] Stutterheim, S.E., et al., HIV-related stigma in African and Afro-Caribbean communities in the Netherlands: Manifestations, consequences and coping. Psychology \& Health, 2012. 27(4): p. 395-411.

[14] Leblanc, N.M., D.D. Flores, and J. Barroso, Facilitators and Barriers to HIV Screening: A Qualitative Meta-Synthesis. Qualitative Health Research, 2016. 26(3): p. 294-306.

[15] Reidpath, D.D. and K.Y. Chan, A method for the quantitative analysis of the layering of $H I V-$ related stigma. AIDS Care, 2005. 17(4): p. 42532. 
[16] Lekas, H.M., K. Siegel, and J. Leider, Felt and enacted stigma among HIV/HCV-coinfected adults: the impact of stigma layering. Qualitative Health Research, 2011. 21(9): p. 1205-19.

[17] Earnshaw, V.A., et al., Intersectionality of internalized HIV stigma and internalized substance use stigma: Implications for depressive symptoms. Journal of Health Psychology, 2015.

[18] Whitaker, T., P. Ryan, and G. Cox, Stigmatization among drug-using sex workers accessing support services in Dublin. Qualitative Health Research, 2011. 21(8): p. 1086-100.

[19] Chakrapani, V., et al., Barriers to antiretroviral treatment access for injecting drug users living with HIV in Chennai, South India. AIDS Care, 2014. 26(7): p. 835-41.

[20] Ding, L., et al., Predictors and consequences of negative physician attitudes toward HIVinfected injection drug users. Archives of Internal Medicine, 2005. 165(6): p. 618-23.

[21] Dickson-Gomez, J., et al., HIV Treatment for Alcohol and Non-Injection Drug Users in El Salvador. Qualitative Health Research, 2015. 25(12): p. 1719-32.

[22] Saw, Y.M., et al., What are the factors associated with HIV testing among male injecting and non-injecting drug users in Lashio, Myanmar: a cross-sectional study. BMJ Open, 2013. 3(6).

[23] Ti, L., et al., HIV test avoidance among people who inject drugs in Thailand. AIDS and Behavior, 2013. 17(7): p. 2474-8.

[24] Altice, F.L., et al., Treatment of medical, psychiatric, and substance-use comorbidities in people infected with HIV who use drugs. The Lancet, 2010. 376(9738): p. 367-87.

[25] Levi-Minzi, M.A. and H.L. Surratt, HIV stigma among substance abusing people living with HIV/AIDS: implications for HIV treatment. AIDS Patient Care and STDS, 2014. 28(8): p. 442-51.

[26] Stutterheim, S.E., et al., Disclosure of HIV status to health care providers in the Netherlands: A qualitative study. Journal of the Association of Nurses in AIDS Care, 2016. 27(4): p. 485-94.

[27] Malta, M., et al., Adherence to antiretroviral therapy among HIV-infected drug users: a meta-analysis. AIDS and Behavior, 2010. 14(4): p. 731-47.

[28] Salter, M.L., et al., Influence of Perceived Secondary Stigma and Family on the Response to HIV Infection Among Injection Drug Users in Vietnam. AIDS Education and Prevention, 2010. 22(6): p. 558-70.
[29] Latkin, C., et al., The relationship between drug user stigma and depression among inner-city drug users in Baltimore, MD. Journal of Urban Health, 2013. 90(1): p. 147-56.

[30] Flick, U., An Introduction to Qualitative Research. 4th ed. 2009, London, UK: Sage.

[31] Thomas, D.R., A general inductive approach for analyzing qualitative evaluation data. American Journal of Evaluation, 2006. 27(2): p. 237-246.

[32] Thorne, S., Toward methodological emancipation in applied health research. Qualitative Health Research, 2011. 21(4): p. 443-53.

[33] HIV Monitoring Foundation, Monitoring Report 2016: Human Immunodeficiency Virus (HIV) infection in the Netherlands. 2016, HIV Monitoring Foundation: Amsterdam, the Netherlands.

[34] Stutterheim, S.E., et al., Patient and provider perspectives on HIV and HIV-related stigma in Dutch health care settings. AIDS Patient Care and STDS, 2014. 28(12): p. 652-65.

[35] Crow, G. and A. Powell. What is "missing data"in qualitative research? in 4th ESRC Research Methods Festival. 2010. St. Catherine's College, Oxford, UK.

[36] Jurgens, R., et al., People who use drugs, HIV, and human rights. The Lancet, 2010. 376(9739): p. 475-85.

[37] Tindal, C., K. Cook, and N. Foster, Theorising stigma and the experiences of injecting drug users in Australia. Australian Journal of Primary Health, 2010. 16(2): p. 119-25.

[38] Treloar, C. and T. Rhodes, The lived experience of hepatitis $C$ and its treatment among injecting drug users: qualitative synthesis. Qualitative Health Research, 2009. 19(9): p. 1321-34.

[39] Wolfe, D., M.P. Carrieri, and D. Shepard, Treatment and care for injecting drug users with HIV infection: a review of barriers and ways forward. The Lancet, 2010. 376(9738): p. 355-66.

[40] Werb, D., et al., Risk of resistance to highly active antiretroviral therapy among HIVpositive injecting drug users: a meta-analysis. The Lancet, 2010. 10(7): p. 464-9.

[41] Semple, S.J., et al., Factors associated with experiences of stigma in a sample of HIVpositive, methamphetamine-using men who have sex with men. Drug and Alcohol Dependence, 2012. 125(1-2): p. 154-9.

[42] Stajduhar, K.I., et al., Missed opportunities: injection drug use and HIV/AIDS in Victoria, Canada. International Journal of Drug Policy, 2004. 15(2004): p. 171-181. 
[43] Chan, K.Y., et al., Stigmatization of AIDS patients: disentangling Thai nursing students' attitudes towards HIV/AIDS, drug use, and commercial sex. AIDS and Behavior, 2008. 12(1): p. 146-57.

[44] McGinty, E.E., et al., Portraying mental illness and drug addiction as treatable health conditions: Effects of a randomized experiment on stigma and discrimination. Social Science \& Medicine, 2015. 126: p. 73-85.

[45] Cook, J.E., et al., Intervening within and across levels: a multilevel approach to stigma and public health. Social Science \& Medicine, 2014. 103: p. 101-9.

[46] Bos, A.E.R., et al., Stigma: Advances in theory and research. Basic and Applied Social Psychology, 2013. 35(1): p. 1-9.

[47] van Empelen, P., et al., Effective methods to change sex-risk among drug users: a review of psychosocial interventions. Social Science \& Medicine, 2003. 57(9): p. 1593-608.
[48] Bartholomew Eldredge, L.K., et al., Planning health promotion programs: An intervention mapping approach. Fourth Edition ed. Planning health promotion programs: An intervention mapping approach (4th ed.). 2016, San Francisco, CA: Jossey-Bass.

[49] Li, L., et al., Diffusion of positive AIDS care messages among service providers in China. AIDS Education and Prevention, 2007. 19(6): p. 511-8.

[50] Jacobson, N., Dignity violation in health care. Qualitative Health Research, 2009. 19(11): p. 1536-47.

[51] Jin, H., et al., An assessment of health-care students' attitudes toward patients with or at high risk for HIV: implications for education and cultural competency. AIDS Care, 2014.

[52] Yiu, J.W., et al., Effectiveness of a knowledgecontact program in improving nursing students' attitudes and emotional competence in serving people living with HIV/AIDS. Social Science and Medicine, 2010. 71(1): p. 38-4.

Citation: Sarah E Stutterheim, Hilde Roberts, Ineke Baas, Ronald Brands, Jeannot Schmidt, Lilian Lechner et al., Stigma in the Dutch Health Care Sector: HIV-Positive Substance Users' Experiences and Health Care Providers' Perspectives, ARC Journal of Nursing and Healthcare. 2017; 3(3): 11-22. doi: dx.doi.org/ 10.20431/2455-4324.0303002.

Copyright: (C) 2017 Authors. This is an open-access article distributed under the terms of the Creative Commons Attribution License, which permits unrestricted use, distribution, and reproduction in any medium, provided the original author and source are credited. 